\title{
Psychopathology and causal explanation in practice. A critical note on Heidegger's Zollikon Seminars
}

\author{
Gerben Meynen · Jacco Verburgt
}

Published online: 1 July 2008

(c) The Author(s) 2008

\begin{abstract}
From 1959 until 1969, Heidegger lectured to psychiatrists and psychiatry students at the University of Zurich Psychiatric Clinic and in Zollikon. The transcriptions of these lectures were published as the Zollikon Seminars. In these seminars Heidegger is highly critical of psychoanalysis, because of its causal and objectifying approach to the human being. In general, Heidegger considers it an objectification or even an elimination of the human being to approach a patient from a causal perspective. In our view Heidegger has overlooked the peculiar nature and complexity of psychotherapy and psychiatry, namely that psychiatry is not just a discipline that combines a hermeneutical approach and a natural science approach on a theoretical level, but it also deals with psychopathology in practice. We argue, also referring to Strawson and Gadamer, that in psychiatric practice causal explanation and hermeneutic understanding are no mutually exclusive approaches. We conclude that the encounter of philosophy and psychiatry in matters of causality and motivation could be particularly fruitful when the practical situation is addressed, recognizing the special character of psychopathology.
\end{abstract}

\footnotetext{
G. Meynen $(\square)$

Department of Philosophy, VU University Amsterdam, EMGO Institute VU medical center, De Boelelaan 1105, 1081 HV Amsterdam, The Netherlands

e-mail: g.meynen@ph.vu.nl

J. Verburgt

Department of Philosophy, VU University Amsterdam, De Boelelaan 1105, 1081 HV Amsterdam, The Netherlands e-mail: jhp.verburgt@ph.vu.nl
}

Keywords Psychopathology · Causal explanation · Heidegger · Motivation · Hermeneutics · Psychiatry · Psychotherapy · Freedom · Strawson · Philosophy

\section{Introduction}

The interface between philosophy and psychiatry is gaining more and more interest. ${ }^{1}$ Within this context Karl Jaspers, philosopher and psychiatrist, is mentioned quite regularly. ${ }^{2}$ Heidegger, however, one of the most influential philosophers of the twentieth century, is usually not paid much attention to. ${ }^{3}$ Yet, the link between Heidegger and psychiatry seems to be rather obvious. From 1959 until 1969, Heidegger lectured to psychiatrists and psychiatry students at the University of Zurich Psychiatric Clinic and in Zollikon. The transcriptions of these lectures were published as the Zollikon Seminars by the psychiatrist and initiator of these lecture meetings, Medard Boss. Boss writes:

From the very beginning, as he himself once admitted, Heidegger had set great hope on an association with a doctor who had a seemingly extensive understanding of his [Heidegger's] thought. He saw the possibility that his philosophical insights would not be confined merely to the philosopher's quarters

\footnotetext{
${ }^{1}$ See, e.g., the Oxford series International Perspectives in Philosophy and Psychiatry, edited by Fulford, Sadler, Stanghellini, Morris. And, more in specific the Oxford Textbook of Philosophy of Psychiatry, edited by Fulford, Thornton and Graham (2006).

2 See, e.g., Bolton and Hill 1996, p. xvii, and also D. Denys (2007), 'How new is the new philosophy of psychiatry?'

3 A recent exception is Svenaeus (2007). It has to be noted that also in the Oxford Textbook of Philosophy of Psychiatry (2006) Heidegger is being paid attention to.
} 
but also might benefit many more people, especially people in need of help. ${ }^{4}$

The Zollikon Seminars appeared in German in 1987 (edited by Boss) and were translated into English in 2001. In these lectures many different topics are discussed, for instance the nature of the human body ${ }^{5}$ and the measurability of phenomena. One important theme is the issue of causal explanation in relation to psychotherapy. It is this topic that we will explore in this paper. First, we will focus on Heidegger's criticism of causal explanation, especially in Freudian psychoanalysis. Second, we will argue that Heidegger has overlooked the complexity of the practice of psychotherapy and psychiatry. We will illustrate our objection to Heidegger's criticism of causal explanation in psychopathological conditions by presenting two examples taken from everyday medical practice and by pointing out that causal explanation in the practice of psychiatry and psychotherapy is not necessarily 'inhumane', i.e., eliminating the human being qua human being (reducing her to an object), as Heidegger seems to suggest.

Before starting our discussion of Heidegger's criticism of causal explanation in psychotherapy, however, we want to make three introductory remarks. First, under the title Zollikon Seminars we do not only find the transcriptions of Heidegger's lectures to psychiatrists and psychiatry students. In fact, the Zollikon Seminars consist of three parts. Part one contains the protocols or transcriptions of the lectures (from 1959-1969), part two contains accounts of conversations between Heidegger and the psychiatrist Boss (from 1961-1972), and part three contains letters from Heidegger to Boss (1947-1971). In the Introduction Boss points out that the text of the Zollikon Seminars is trustworthy: Heidegger has seen the transcripts of the lectures and has been able to correct them (Heidegger 1987, p. XIV). And also an important part of the conversations has been looked at by Heidegger himself, and the letters, of course, have been written by Heidegger. Boss, though, has made a selection, not only from the letters, but often he also has omitted parts of their contents.

Second, as will become clear in the next section, Heidegger has been very critical towards Freud and psychoanalysis. Yet, during the second half of the twentieth century, Heidegger also inspired psychoanalysists. Usually, Lacan $^{6}$ is referred to as an important example of his

\footnotetext{
$\overline{{ }^{4} \text { Heidegger }}$ (2001, p. xvii), translation adjusted.

5 See Bracken (1999).

${ }^{6}$ Lacan also features in the Zollikon Seminars. Heidegger writes to Boss: "Surely, you also received the thick book by Lacan (Ecrits). For the moment I have not gotten around to reading this obviously baroque text." (Heidegger. 2001 p. 279) Some months later, Heidegger writes to Boss: “(...) I am enclosing a letter from Lacan. It seems to me that the psychiatrist needs a psychiatrist. Perhaps you
}

influence on the development of psychoanalytic thought. ${ }^{7}$ Heidegger's fierce criticism of psychoanalysis on the one hand and the role of Heidegger's philosophy in psychoanalytic thought on the other, has led to a debate about the compatibility of 'Heidegger' and 'Freud' .8 Although such a debate may certainly have its importance, we will not engage into it. ${ }^{9}$ We will only discuss Heidegger's critique on psychoanalysis in relation the focus of our paper, namely the role of causal explanation in psychotherapy and medical practice.

Third, even though Heidegger's philosophy is often considered 'obscure', the confrontation with psychiatrists during the 1960s seems to bring forward a more 'accessible' Heidegger, while most of the central themes of his thought remain present.

\section{Heidegger's criticism of causal explanation, in particular in psychoanalysis}

It is well known that Heidegger is highly critical about causal explanation in psychoanalysis in the Zollikon Seminars. ${ }^{10}$ In this section we will discuss some relevant passages in which Heidegger addresses Freud's psychoanalysis and metapsychology. The first quote is taken from one of his conversations with Medard Boss in which Heidegger remarks:

The human being is essentially in need of help because he is always in danger of losing himself and of not coming to grips with himself. This danger is connected with the human being's freedom. The entire question of the human being's capacity for being ill is connected with the imperfection of his unfolding essence. Each illness is a loss of freedom, a constriction of the possibility for living. The "psychoanalytic life history" is by no means a history, but a naturalistic chain of causes, a chain of cause and effect, and even more a constructed one. ${ }^{11}$

\footnotetext{
Footnote 6 continued

can write a few short notes for me when you send it back." (Heidegger, 2001 pp. 280-1)

7 See, e.g., Lang, Brunnhuber and Wagner (2003).

${ }^{8}$ See Jackson (2007, p. 251): As Jackson points out: "The theme of the possibility or impossibility of the compatibility between Heideggerian philosophy and Freudian metapsychology has been taken up in various ways. Arguments in favor of such a compatibility often rely on an appeal to the psychoanalysis of Jacques Lacan, whose reading of Freud seems to have been inspired in certain ways by Heidegger." See also Bolton and Hill (1996, p. xv).

${ }^{9}$ See for this debate, e.g., F. Dallmayr. Heidegger and Freud. Political Psychology, Vol. 14, No. 2, Special Issue: Political Theory and Political Psychology (Jun., 1993), pp. 235-253.

10 Jackson (2007, p. 251).

11 Heidegger 2001, pp. 157-158, translation slightly adjusted.
} 
This quote shows the central problem with psychoanalysis according to Heidegger: psychoanalysis understands a person's history as a causal chain, and a 'constructed' one. In the same conversation Heidegger even raises the question whether or not the human being is at all present in Freudian libido theory:

Is the human being present within the total construct of Freudian libido theory at all? (...) Attempts to explain human phenomena on the basis of instincts have the characteristic method of a science whose object field is not the human being at all but rather mechanics. Therefore, it is fundamentally questionable whether such a method, determined by nonhuman objectivity, is able to assert anything about the human being as a human being. ${ }^{12}$

Heidegger also suggests that Freud was specifically trying to find a causal approach to human phenomena. According to Heidegger such an approach could not be derived from 'conscious' human activity, and therefore Freud had to invent the 'unconscious':

For conscious human phenomena, he [Freud] also postulates an unbroken [chain] of explanation, that is, the continuity of causal connections. Since there is no such thing "within consciousness," he has to invent "the unconscious" in which there must be an unbroken [chain of] causal connections. The postulate is the complete explanation of psychical life whereby explanation [Erklären] and understanding [Verstehen] are identified. This postulate is not derived from the psychical phenomena themselves but is a postulate of modern natural science. ${ }^{13}$

It is fair to say that for Heidegger the essential problem in Freud's theory is the unconscious, which enabled Freud to conceive of a human being as a causally determined object. Therefore, Heidegger (2001, p. 254) rejects the concept of the unconscious, and speaks about "the fatal distinction between the conscious and the unconscious". We will not enter into discussions about whether Heidegger is right in his conception that psychoanalysis and the notion of the unconscious necessarily bring an exclusively causal perspective, like in the natural sciences. But it becomes clear that Heidegger considers Freud's

\footnotetext{
$\overline{12}$ Heidegger 2001, pp. 172. Cf. Dallmayr (1993, p. 235): “The main difference derives from Heidegger's objections to a positivist construal of depth understanding, a construal which relies narrowly on libidinal drives seen as a psycho-somatic causal mechanism. As opposed to this construal, Heidegger proposes the approach of "existential analysis" (Daseinsanalyse) which accentuates human openness to "being" mediated through human embodied insertion in the world and in temporality."

${ }^{13}$ Heidegger 2001, pp. 207-208, translation sligthly adjusted.
}

undertaking as a fundamentally causal theory, akin to the natural sciences. Heidegger (2001, p. 208), however, also understands Freud's metapsychology as rooted in a philosophical current: "Freud's metapsychology is the application of Neo-Kantian philosophy to the human being. On the one hand, he [Freud] has the natural sciences, and on the other hand, the Kantian theory of objectivity."

So, Freud combined natural science on the one hand and Neo-Kantian philosophy on the other in his approach of the human being. Now, one might expect that Heidegger would not favour a combination of natural science and philosophy as far as an approach to the human being is concerned. Yet, surprisingly, Heidegger considers the encounter of natural science and philosophy with respect to psychiatry (implying the approach to the human being in medical practice) as 'productive' and 'exciting': "It is especially the case in psychiatry that the continuous encounter between the thinking of the natural scientist and that of the philosopher is very productive and exciting." (Heidegger 2001, p. 238) Apparently, Heidegger's discussion of the encounter is not just born from negative criticism, but also out of the search for new possibilities and challenges.

However, according to Heidegger, as long as a causal theoretical perspective is applied, this implies objectification. For theories that "remain bound to the principle of causality, (...) go along with the objectification of everything that is. In this way they have already blocked forever the view of the human being's proper being-in-theworld." 14 (Heidegger 2001, p. 233) Now, according to Heidegger, objectification fundamentally hampers psychotherapy, since if

“(...) psychotherapy can be done only if one objectifies the being beforehand, because what is decisive thereby is psychotherapy and not the existence of the human being, and because one can [supposedly] only do therapy, which is a concerned handling of objects, and thus something purely technical, then the outcome of such psychotherapy cannot result in a healthier human being. In such a therapy, the human being is finally eliminated. At best, such a therapy could [only] result in a more polished object." 15

\footnotetext{
14 'Being-in-the-world' is Heidegger's term for the nature of our own being (Being and Time 2002, pp. 78ff). Cf. Heidegger 2001, p. 196: "It would be necessary for medicine to search for the essential potentiality-to-be human. If one looks for foundation in the causalgenetic sense, one abandons the human being's essence beforehand, and thus one misses the question of what being human is." $\mathrm{Cf}$. Heidegger 2001, pp. 209-210: "Causality plays a role in calculating the lawlike sequence of one state after another. (...) I am surely not a sequence of processes. That is not human."

${ }^{15}$ Heidegger 2001, p. 215, translation slightly adjusted.
} 
As becomes clear in this quote, Heidegger's theoretical considerations culminate in this far reaching statement that the human being would be finally eliminated in an objectifying therapeutic approach. But what precisely is eliminated in a causal approach? According to Heidegger, "Causality is an idea, an ontological determination. It belongs to the determination of the ontological structure of nature. Motivation refers to the human being's existence in the world as a being who acts and experiences." ${ }^{16} \mathrm{Cau}-$ sality has, thus, to be distinguished from motivation, the former being about nature, the latter being about a human being-and psychiatry and psychotherapy are about the human being. ${ }^{17}$ Yet, we could suppose that from the causal perspective, it is still possible to understand the human being as a motivated being. But this does not seem to be Heidegger's view, as becomes clear when he phrases the distinction between causality and motivation in the well known pair of determinism and freedom:

Determinism denies freedom and yet by denying it, it already must presuppose a certain idea of freedom. Freedom as represented in the natural sciences has always been understood as non-causal, as an a-causal occurrence. Therefore, determinism [as causal determination] remains outside of freedom from the start. Freedom has nothing to do with causality. Freedom is to be free and open for being claimed by something. This claim is then the ground of action, the motive. It has nothing whatsoever to do with causal chains. What claims [the human being] is the motive for human response. Being open for a claim lies outside the dimension of causality. Thus, determinism does not even come close to realm of freedom in the first place. It cannot say anything about freedom at all. Therefore, as far as freedom is concerned it does not matter at all whether we know all the causes or none of the causes, or how many causes a thing has. ${ }^{18}$

So, there is a fundamental rift between the realm of motivation and freedom on the one hand, and the domain of nature and causality on the other. A causal approach will

\footnotetext{
$\overline{16}$ Heidegger 2001 , p. 24, translation slightly adjusted. See also in a letter to Boss: "But it also seems important to make clear to the seminar participants what fundamental opposition lies behind the properly made distinction between causality and motivation. It must become clear that it is not only concerned with a methodological (technical-practical) distinction, but with a fundamentally different way of determining being human and the determining the human being's position in contemporary world civilization. Only by reflecting on this does the full importance of the distinction come to light." (Heidegger 2001, p. 280)

17 Heidegger (2001, p. 135): “The theme of physics is inanimate nature. The theme of psychiatry and psychotherapy is the human being."

18 Heidegger 2001, p. 217.
}

never be able to recognize and to do justice to the human being as a motivated and free being. ${ }^{19}$ Yet, according to Heidegger, in the end "[w]e do psychology, sociology, and psychotherapy in order to help the human being reach the goal of adjustment and freedom in the broadest sense." 20

As mentioned above, Heidegger's reconstruction of Freud's endeavor is that the postulate of natural sciences on the one hand, and Kantian philosophy on the other led him to develop his metapsychology. In The Essence of Human Freedom, written almost forty years before the quoted statement on freedom and causality, Heidegger criticized Kant for approaching freedom from the perspective of causality. ${ }^{21}$ Apparently, he has not essentially changed his mind. So, in this vein, the application of a causal theory on a human being seeking help from a doctor or psychotherapist, will not do justice to him or her as a free human being. Causal theories should, so seems to be the message, be left aside in psychotherapy if the realm of motivation and freedom is to be preserved in the therapeutic context. However, in our view, the actual situation in psychotherapy and psychiatry is more complex than Heidegger suggests. ${ }^{22}$

\section{Does Heidegger overlook the praxis of psychiatry and the nature of psychopathology?}

In the Zollikon Seminars Heidegger is lecturing to psychiatrists about psychotherapy; he is not lecturing to psychologists. Yet, Heidegger is concerned with general (meta)psychological theories and considerations. Now, as Bolton and Hill state, "[i]nevitably psychiatry has inherited all the philosophical or conceptual problems of psychology, including the problem of meaning and causality, but it faces further specific ones of its own." (1996, p. xvi, our

\footnotetext{
${ }^{19}$ Within the scope of this paper we will not further discuss the issue of freedom and determinism. We use this quote by Heidegger to show that within his philosophy there is a radical distinction between the domain of motivation on the one hand, and the domain of causality on the other.

${ }^{20}$ Heidegger 2001, p. 154.

${ }^{21}$ Heidegger (2005, pp. 205-208). Cf. Muchada (2005): "At the close of his lecture course on the Essence of Human Freedom, Heidegger suggests that while for Kant freedom is a kind of causality, understood in terms of the ontological difference, the reverse is true: causality is grounded in freedom. This is the case because causality is a way of understanding the being of beings (Sein des Seiendes), such understanding however is rooted in the "letting something stand over against as something given'."

${ }^{22}$ Cf. Fulford, Thornton and Graham (2006): "One recurrent theme of this book [Oxford Textbook of Philosophy and Psychiatry] is the relation between reasons and causes in psychiatry. Whereas many disciplines operate with one or other form of explanation and interpretation, psychiatry operates with both. Nowhere is the tension between the two as great as the issue of freedom versus causal determinism."
} 
italics) Heidegger does pay attention to the problems inherited of psychology, but he does not seem to pay attention to what might be specifically relevant to psychiatrists and psychotherapists: psychopathology. In the practice of their work psychiatrists and psychotherapists have to do with 'illness' or 'mental disorder'. In our view, there is a relevant difference between general psychology and psychopathology-relevant to psychiatrists and to the issue of causal explanation: "There are certainly problems with construing meaningful mental states as causes of behavior already in the normal case, but there is a further reason for doubting the relevance of meaningful explanation in the case of disorder." (Bolton and Hill 1996, xvi, our italics) According to Bolton and Hill "the reason is simple, on the surface, namely, that the notion of disorder is applied precisely at the point where meaning comes to an end." The notion of (mental) disorder comes into play exactly on the point "when there is (serious) failure of meaningful connection between mental states and reality, or among mental states, or between mental states and action." So, in this sense, mental disorders are conceptually related with the "breakdown of meaning", and at such instances it is plausible that we require "explanation in terms of non-meaningful processes". In these situations we may posit mechanisms that do not have to do with 'meaning', like physical causation. This apparently straightforward connection between (mental) disorder and non-meaningful or causal explanation is "overshadowed, however, because the issue of where the limits of the meaningful lie presses hard." 23

Bolton and Hill clearly show the unique situation in the case of psychopathology. The issue of causal explanation seems to be implied in the concept of psychopathology itself. Yet, it is unclear how and to which extent this exactly is the case. But, surely, the fact that this matter is not settled, does not imply that the issue itself becomes irrelevant - on the contrary. It is highly important to consider the issue of whether, indeed, psychopathology already implies a form of causal explanation, and to which extent. Bolton and Hill correctly state that psychiatry incorporates all the philosophical problems of psychology. So, Heidegger is perfectly right in discussing psychological theories when lecturing to psychiatrists. In fact, psychiatry is often considered to be a discipline composed of a set of activities subsuming neuroscientific, psychological and sociological approaches. ${ }^{24}$ Yet, Heidegger is also interested

\footnotetext{
23 All quotes from Bolton and Hill (1996, p. xvi).

${ }^{24}$ See Brendel (2000): "Like many of the philosophers and psychiatrists discussed (...), Fulford and Wakefield have viewed psychiatry as a pluralistic set of activities subsuming neuroscience, psychology, sociology, and ethics. Their notion of conceptual pluralism in psychiatry can serve as the basis for humane and wellbalanced clinical services."
}

in the perspective of psychiatric practice: the doctor/therapist and her patient. More specifically, Heidegger's concern seems to be, as we saw above, to do justice to the patient as a human being in this practical situation. And Heidegger seems to realize that this therapeutic situation calls for a specific approach, for he writes: "In order to be able to give a sufficiently clear interpretation of the relationship between the psychiatrist and the patient (...), some medical experience, which I lack, is necessary as well. Here, as elsewhere, I am dependent on the cooperation of the seminar participants." 25 Heidegger shows some hesitation here, as it comes to the actual practice of psychotherapy and psychiatry; he acknowledges the relevance of it, realizing that his knowledge is not sufficient to analyze this situation, and that he is in need of psychiatric expertise.

In an approach that engages into the practical doctorpatient relationship it is of course important to pay attention to the fact that the identification of a psychopathological condition in the therapeutic situation might already imply the absence or "breakdown" (Bolton and Hill, xvi) of meaning. In other words, even aside from scientific and (meta)psychological theories, there may be some understanding about causality at work in the practical situation of psychotherapy, precisely in the way Bolton and Hill have explained. In our view, because Heidegger is interested in the therapeutic situation (that is characteristic for psychopathology, not for psychology), he should have paid attention to what is specific about it, in contrast with the theoretical perspective of psychology. So, while it may be that, as Mayr (Heidegger 2001, p. 312) writes in the Translator's Afterword to the Zollikon Seminars, "Heidegger wanted to free psychology (and its relevant subdisciplines) from its uncritical adherence to Cartesian "thing" ontology and its concomitant trappings," when addressing the practice of therapy Heidegger should not have limited his account to psychological theories and their adherence to a specific ontology. Psychology is a science using theories concerning general mental functioning, while psychiatry is a medical practice using theories concerning pathological mental functioning.

Of course, one should consider that psychiatry was much more in the hands of psychoanalysts in the sixties than it is today and that psychology for some part equaled Freudian metapsychology. ${ }^{26}$ Metapsychology was one of the super theories of psychiatry in the sixties. As far as the theory of psychiatry is concerned it was understandable

\footnotetext{
$\overline{25}$ Heidegger 2001, p. 274. See also, from a letter to Boss: "You know that the problems of psychopathology and psychotherapy regarding their principles interest me very much, although I lack the technical knowledge and command of the actual research." (Heidegger 2001, p. 237)

${ }^{26}$ See, e.g., Svenaeus (2001, p. 40).
} 
that Heidegger addressed Freudian metapsychology when lecturing to psychiatrists. Yet, a difference remains between the understanding of 'normal' behavior and the explanation of psychopathological behavior (as Bolton and Hill discussed). So, at least the difference between psychiatric practice and psychological theory does not seem to be sufficiently recognized in the Zollikon Seminars. In short, Heidegger does not pay attention to the way causal explanations and hermeneutic understanding seem to be intertwined in psychiatric practice. ${ }^{27}$

\section{Causal explanation at work}

In section "Heidegger's criticism of causal explanation, in particular in psychoanalysis" we discussed that Heidegger considered the human being to be eliminated in a causal explanatory approach. In this section we will address our critical question: Is it really 'inhumane', i.e. objectifying or eliminating the human being, for a doctor to apply causal explanation when confronted with a patient? ${ }^{28}$ First, we will present two familiar examples, taken from everyday medical practice, to deal with this question. One example derived from a non-psychopathological situation (which functions as a footboard for the second example) and one derived from a psychopathological one. The purpose of these examples is to bring forward the importance of practice. Secondly, we will turn to Strawson and Gadamer for further support of our claim about the relevance of the practice of psychiatry.

\section{Example 1: A non-psychopathological example}

Suppose a person has a broken leg. He will be happy that a doctor applies some causal explanation to this broken lega part of the patient-in order to fix it. We do not consider it 'inhumane', but rather 'humane' that she does apply such an explanation in order to treat the patient. The doctor, herself being a human being, seems to know when and in what way to apply a causal theory. And, most importantly, the application of the causal theory about a broken leg is motivated by the fact that she recognizes that she is confronted not with an object, but with another human being.

\footnotetext{
27 See also Svenaeus (2001) who approaches the intertwinement of practice and theory from the perspective of a meeting of a patient and doctor in which the concept of a dialogue is central: "What characterizes a meeting, in contrast to scientific explanatory understanding, is (...) mutual, shared understanding. This does not mean that the understanding of the two persons who meet must be totally shared in the sense of being the same understanding." (p. 146)

28 Within the context of this paper we will not address Heidegger's specific understanding of the concept of 'humanism'. Cf. Heidegger's Letter on "Humanism" (1998). See Heidegger (2001, p. 154) for the notion 'humanitas'.
}

So, she knows when and how (to which extent) to apply a causal theory. And the application is not opposite to seeing the person as a human being, but motivated by it.

Heidegger seems to see this point (at least in part) but he also seems to have a certain opinion about medical specialists (and psychiatrists are medical specialists), as expressed in a conversation with Boss ${ }^{29}$ :

"For instance, when I give quinine to someone suffering from malaria, I am merely the occasion for the quinine killing the amoebas. The patient's body [as cause] then heals him. If the physician understands his role as merely being-in-the-occasion [Anlasssein], then it is indeed still possible that the beingwith [the patient] can continue. But if the physician were to understand himself in such a way that he has brought about [caused] the healing of the patient as an "object," then the being human and the being-with are lost. As a physician one must, as it were, stand back and let the other human being be. These [dealings with the patient as "being-with" or as an "object"] are entirely different modes of comportment, which cannot be distinguished from outside at all. Herein lies the existential difference between a family doctor and a specialist in a clinic. It is characteristic that family doctors are a dying breed." ${ }^{30}$

This view on medical specialists would mean that it makes a fundamental difference whether, with a broken leg, one is transported to a clinic or to the general practitioner. Although some people may recognize parts of what Heidegger says here, it seems an oversimplification, and it shows some black-and-white view on medical practice, that does not seem to be very helpful to understand medical practice. Heidegger does not pay attention to the fact that in a therapeutic relation, causal reasoning can be applied-not just opposite to seeing a person as a human being, but exactly motivated by the fact that the person is a human being, and he also seems to doubt that such a 'humane' attitude is possible for a medical specialist, like a psychiatrist, or a orthopedic surgeon. Things get more interesting in psychopathology, where it is not about legs, but about minds.

\footnotetext{
${ }^{29}$ Boss himself started a psychiatric school of "Daseinsanalyse" in which he tried to use Heidegger's philosophy to create a theoretical framework for psychiatric practice. In Psychoanalysis and Daseinsanalysis (1963) Boss also discusses causal explanation with respect to psychoanalysis (referred to as "psychodynamics"), and he, like Heidegger, criticizes it: "The concept of "psychodynamics" tries to derive every phenomenon from something else by assuming a causal energy, capable of transforming itself into an appearing thing." (1963, p. 108) And Boss adds on the same page: "(...) we can throw psychodynamics overboard as superfluous baggage."

${ }^{30}$ Heidegger 2001, p. 210-211. One could object that Heidegger, talking about quinine, overlooks the placebo-effect, but we will not address this issue.
} 
Example 2: A psychopathological example

The person with the broken leg is operated upon and during the night he becomes very ill and develops disturbances in orientation and starts accusing the doctor of stealing his properties, while the doctor provides nothing but good care. At first the doctor might feel insulted because of the unjust accusation, for it is clear that the doctor understands the accusation as a verbal act of a human being. But should the doctor feel insulted because of the accusations? Unless she uses some sort of a 'causal explanation', she may feel insulted, and act accordingly. However, as a doctor, she might also take into account the probability that, the patient being very ill and operated upon, has developed a delirium. The accusations, then, have to be primarily understood in a way that the patient is in a bad condition, and that treatment is needed as soon as possible. The words about theft are completely understood as verbal acts of a human being, yet, they are not understood as the 'motivated' accusations that they would be in the normal situation. They are considered as 'caused' - in whatever specific sense, but stillby the condition, a delirium.

In our view, it is not 'inhumane' that this doctor does not consider the words of the patient primarily as 'motivated', but as 'caused' by a mental disturbance due to a severe physical condition. When the doctor would not consider this a 'causal' mechanism, but as fully 'motivated', and if she would, perhaps, be outraged about the accusations and would act accordingly, would there be more 'humanity' in her action? This is of course a rhetoric question. It is not 'inhumane' to apply causal explanation in certain situations of (psycho)pathology. Not recognizing behavior as 'caused', but considering it as 'motivated' may hamper appropriate treatment and result in adverse consequences to the patient.

Suppose the treatment of the patient is successful and he quickly recovers. The next morning he thanks the doctor for her good care. He does not seem to remember much about what happened during the night. Should the doctor consider his gratefulness 'causal behavior', or 'motivated behavior'? We think the latter would apply. But is the doctor more 'humane' now than during the night when she applied causal explanation about the influence of severe physical disturbance on the mind? We don't think so. Both responses can be considered 'humane', and motivated from the understanding that she is dealing not with an object, but with a human being. Although the first response (during the night) can, in addition, be considered a professional response; it can be considered exactly the response one would expect from a doctor.

In order to further develop our critical note on $\mathrm{He}$ idegger's account, we turn to Strawson. In his seminal paper 'Freedom and Resentment' about moral attitudes
Strawson also addresses the therapeutic situation. Strawson distinguishes between two kinds of moral attitudes. The first is the 'participant' attitude, linked to perceiving an agent as part of the moral community. Such a member of the moral community is a true candidate for praise and blame. The second type of attitude is the 'objective' attitude $(2003$, p. 80$)$. This attitude we have, according to Strawson, towards children (to some extent) and towards adults suffering from mental disorder (see, e.g., Strawson 2003 , pp. 78, 79, 81). Strawson states the following with respect to the attitude of a psychoanalyst to his patient:

"His objectivity of attitude, his suspension of ordinary reactive attitudes, is profoundly modified by the fact that the aim of the enterprise is to make such suspension unnecessary or less necessary. Here we may and do naturally speak of restoring the agent's freedom. But here the restoring of freedom means bringing it about that the agent's behavior shall be intelligible in terms of conscious purposes rather than in terms only of unconscious purposes. This is the object of the enterprise; and it is in sofar as this object is attained that the suspension or half-suspension of ordinary moral attitudes is deemed no longer necessary or appropriate." (p. 88)

Strawson pays attention to the fact that in a psychotherapeutic situation there is an objectifying stance or attitude at work in order to make a 'participant' attitude possible. This is in line with our criticism of Heidegger, as far as the alleged 'inhumanity' of an objectifying attitude is concerned in psychiatric practice.

The difference between Strawson and our view is that Strawson seems not to be particularly interested in the exact nature of these attitudes and how they come about, and what makes a psychiatrist's attitudes change, ${ }^{31}$ while we propose that precisely the analysis of these attitudes could be valuable to understand our intuitions about causal explanation and meaning. So, while Strawson repeatedly refers to mental disorders and even to therapy and the 'psychoanalyst', he does not indicate that the psychiatric or therapeutic situation as such should be studied philosophically or interdisciplinary. ${ }^{32}$ Strawson seems to take our

\footnotetext{
31 Strawson himself is mainly interested in finding a solution to the problem of determinism and moral responsibility or freedom. His paper is not directly about causal explanation. Yet, it is clear that Strawson is not so much concerned with the exact causes of these reactive attitudes (2003, p.77).

${ }^{32}$ While Strawson clearly indicates that psychology has changed our view about moral responsibility, he also claims a separate position for the philosopher who has "to take account of the facts in all their bearings; we are not to suppose that we are required, or permitted, as philosophers, to regard ourselves, as human beings, as detached from the attitudes which, as scientists, we study with detachment." (2003, p. 93)
} 
attitudes and the psychiatrist's attitudes for granted. He perceives them as some sort of 'commitment' that is "part of the general framework of human life" (2003, p.83). "The existence of the general framework of attitudes itself is something we are given with the fact of human society," as Strawson puts it (2003, p. 91) The commitment and therefore our reactive attitudes are 'in our nature' (2003, p. 87). To Strawson there seems not to be a problem or further issue. ${ }^{33} \mathrm{He}$ does not raise the question when and how the 'objectifying' and 'participating' attitude take turns. Why do we find certain reactive attitudes in psychiatric practice when encountering persons suffering from mental disorder, what brings them about?

The importance of a special focus on the practice of psychiatry can be made clear by referring to a pupil of Heidegger, Hans-Georg Gadamer. He writes in the chapter on hermeneutics and psychiatry in his The Enigma of Health:

"Praxis, however, is not merely an application of scientific knowledge. Rather, aspects of praxis react back on research, and the results of research must consistently prove and confirm themselves in turn with reference to praxis. There are, then, good reasons why doctors do not see their profession as equivalent either to that of the scientist or researcher, or to that of a mere technician, who would simply 'apply' scientific knowledge and discoveries with the purpose of restoring health. Part of what a doctor does closely resembles an art, and is something which cannot be conveyed through theoretical instruction. It is this which it is appropriate to call the 'art of healing'. Praxis is more than the mere application of knowledge. And 'practice' refers to the complete sphere of life of the medical profession, and not simply to 'the practice' as one specific workplace among others in the whole world of work. Praxis possesses its own unique world." ${ }^{34}$ (Gadamer $1996 \mathrm{p}$. 163)

The implication of this is that psychiatry is not just the discipline where hermeneutics and psychological or physiological theory meet (which is the focus of Bolton and Hill), but that the practice of psychiatry could bring forward its own insights in our 'attitudes' or intuitions about causality and motivation. Practice cannot be reduced to the application of theoretical knowledge. In our view, it was no

\footnotetext{
33 We cannot go into further detail of Strawson's account. Yet, we would like to add that his account is meant to leave open the compatibility of freedom and determinism, while Heidegger takes a radical position about the 'incompatibility' in the Zollikon Seminars, as we have seen.

${ }^{34}$ Cf. Svenaeus (2001, especially part 3 on the hermeneutics of medicine).
}

accident that Strawson in his famous paper referred to mental disorders and to a psychoanalyst. Being confronted with mental disorders our attitudes and intuitions are put to the test.

\section{Psychopathology and causal explanation}

Causal explanation in some form seems to be present in everyday medical practice. As far as a mental disturbance is concerned, as in a delirium, causal explanation cannot be simply understood from the perspective of mere psychological theories, nor can it be considered to exclude the view on another person as a human being. In some situations causal explanation seems to be at work and appropriate, in other instances the same goes for 'hermeneutic' or 'participating' understanding. And applying causal explanation is itself motivated by recognizing the other person as a human being in need for treatment. This kind of complexity of the doctor-patient relationship is absent in the Zollikon Seminars. And this is where our criticism applies. As far as Heidegger is discussing therapeutic practice, he should at least have acknowledged the peculiar characteristics of it with respect to causal explanation and considering a human being as a human being. ${ }^{35}$

What is valuable about Heidegger's approach, is that he perceives the relevance of the practical psychiatric situation, and that he makes clear that, when we try to understand this practice, philosophers and psychiatrists should cooperate-Heidegger himself signaled that he would be in need of psychiatrists' help should he address medical practice. Yet, our criticism towards Heidegger is that, even while he recognizes the special character of a psychotherapeutic situation, he fails to address the most relevant and most specific point of the practice of psychiatry in relation to causal explanation. Heidegger, therefore, also cannot discuss the issue whether the purpose of causal explanation in psychiatry can be considered to restore the very possibility of applying a hermeneutic or 'participating' approach.

It is exactly in practice, we think, that psychiatry in its encounter of causal theory and philosophy becomes 'exciting' and potentially 'productive'. Here, psychiatry might not only benefit from philosophy, but, in accordance with Fulford (1991), philosophy might even learn something from psychiatry. If Heidegger would have taken the situation of psychiatry seriously in this way, this could also

\footnotetext{
35 A possible third approach which would, in our view, underline the discussed complexity of the therapeutic situation, can be found in Widdershoven and Widdershoven-Heerding (2003), who call this a 'hermeneutic approach'. They dwell on Aristoteles's notion of phronesis, a concept also important to the 'young' Heidegger, Phänomenologische Interpretationen zu Aristoteles (1989).
} 
have meant engaging in new territory, where he, perhaps, could not simply rely on his rather black-and-white criticism of psychology and Freud's metapsychology. When Heidegger would have paid attention to the peculiar phenomenon of psychopathology in relation to causal explanation, it would also have been interesting to see how his intuitions about a radical distinction between the realm of freedom and the realm of causality would work out. Causal explanation and hermeneutic understanding are, as it seems, in medical practice no mutually excluding approaches. So, the practical questions arise: what is a psychopathological condition? When exactly should we apply a causal theory? What are the intuitions or principles by which psychiatrists choose between causal and noncausal explanations? Where lies the border between motives and causation?

It is clear that Heidegger thinks that psychotherapy is in danger ${ }^{36}$ of some hostile take-over by a psychology that applies the methods of the natural sciences to human beings which leads to the objectification or reduction of the patient into an object. We have tried to show that the therapeutic situation may be more complex than that, with causal explanation already at work because the patient's condition has been recognized as psychopathological. Bolton and Hill (1996, p. xvii) are right that "[w]hile the philosophy of psychology has a long and familiar history, and is currently flourishing, the philosophy of psychiatry has been relatively neglected." We think that the philosophy of psychiatry has the best chance to flourish, when it takes on what is specific or unique in psychiatric practice.

\section{Conclusion}

In the Zollikon Seminars Heidegger certainly recognized a vital issue: the relationship between causal explanation on the one hand and hermeneutics (understanding of motivation, the realm freedom) on the other as relevant to psychiatry. Yet, psychiatry is not just a discipline that combines hermeneutical and natural science approaches on a theoretical level, but it essentially deals with psychopathology, which already seems to bring some sort of causal explanation. Moreover, it deals with psychopathology, not just in theory, but also, and principally so, in practice. The unique combination of psychopathology and medical practice is not addressed by Heidegger. We have tried to show that exactly these are the most interesting and promising when philosophy encounters psychiatry in

\footnotetext{
${ }^{36}$ Cf. Heidegger 2001, p. 269: "Viewed from the outside, it might appear almost hopeless to stand up against the reckless power of natural scientific thinking." See also Meynen and Verburgt (2007) in an response to Brassington (2007).
}

matters of causality and motivation. So, our critical note on the Zollikon Seminars implies that the potential of psychiatry to philosophical reasoning on causal explanation and motivated behavior lies first of all in its practice.

Acknowledgements This work is financially supported by NWOVENI research-grant no. 275-20-016.

Open Access This article is distributed under the terms of the Creative Commons Attribution Noncommercial License which permits any noncommercial use, distribution, and reproduction in any medium, provided the original author(s) and source are credited.

\section{References}

Bolton, D., and J. Hill. 1996. Mind, meaning and mental disorder. The nature of causal explanation in psychology and psychiatry. Oxford: Oxford University Press.

Boss, M. 1963. Psychoanalysis and daseinsanalysis. New York: Basic Books.

Bracken, P.J. 1999. The importance of Heidegger for psychiatry. Philosophy, Psychiatry, \& Psychology 6(2): 83-85.

Brassington, I. 2007. On Heidegger, medicine, and the modernity of modern medical technology. Medicine Health Care and Philosophy 10(4): 185-195.

Brendel, D.H. 2000. Philosophy of mind in the Clinic: The relation between causal and meaningful explanation in psychiatry. Harvard Review of Psychiatry 8(4): 184-191.

Dallmayr, F. 1993. 'Heidegger and Freud', political psychology. Political Theory and Political Psychology (Special Issue) 14(2): 235-253.

Denys, D. 2007. How new is the new philosophy of psychiatry? Philosophy, Ethics, and Humanities in Medicine 2: 22.

Fulford, K.W.M. 1991. The potential of medicine as a resource for philosophy. Theoretical Medicine 12: 81-85.

Fulford, K.W.M., J.Z. Sadler, G. Stanghellini, and K.J. Morris (eds.). Oxford series International perspectives in philosophy and psychiatry, Oxford: Oxford University Press.

Fulford, K.W.M., T. Thornton, and G. Graham. 2006. Oxford textbook of philosophy and psychiatry. Oxford: Oxford University Press.

Gadamer, H.-G. 1996. The Enigma of Health. Cambridge: Polity Press.

Heidegger, M. 1989. Phänomenologische Interpretationen zu Aristoteles (1922). In Dilthey-Jahrbuch für Philosophie und Geschichte der Geisteswissenschaften, vol 6, 235-269.

Heidegger, M. 1998. 'Letter on "humanism”" (1946) In Pathmarks, translated by W. Mcneill, 239-276. Cambridge University Press.

Heidegger, M. 2001, Zollikon Seminars. Protocols-conversationsletters, ed. Medard Boss. Evanston, Illinois: Northwestern University Press.

Heidegger, M. 2002. Being and time. Malden: Blackwell.

Heidegger, M. 2005. The essence of human freedom. London, New York: Continuum.

Jackson, J.M. 2007. 'Questioning and the materiality of crisis: Freud and Heidegger'. Philosophy \& Social Criticism 33(2): 251-269.

Lang, H., S. Brunnhuber, and R.F. Wagner. 2003. 'The So-Called Zollikon Seminars: Heidegger as a Psychotherapist'. The Journal of The American Academy of Psychoanalysis and Dynamic Psychotherapy 31: 349-359.

Meynen, G., and J.H.P. Verburgt. 2007. 'Medicine in Danger? Response to: 'On Heidegger, medicine, and the modernity of 
modern medical technology' by Iain Brassington, Medicine, Health Care and Philosophy November 2006 Epub ahead of print'. Medicine, Health Care and Philosophy 10(4): 477-478.

Murchadha, F. 2005. 'Hegel, Nietzsche, Heidegger: thinking Freedom and Philosophy'. British Journal for the History of Philosophy 13(2): 361-373.

Strawson, P.F. 2003. 'Freedom and resentment'. In Free will, ed. G. Watson. Oxford: Oxford University Press.

Sveneus, F. 2001. The hermeneutics of medicine and the phenomenology of health. Steps towards a philosophy of medical practice, Dordrecht: Kluwer.
Svenaeus, F. 2007. 'Do antidepressants affect the self? A phenomenological approach'. Medicine, Health Care and Philosophy 10: 153-166.

Widdershoven, G.A.M., and I. Widderhoven-Heerding. 2003. 'Understanding Dementia: a Hermeneutic Perspective', In Nature and narrative. An introduction to the new philosophy of psychiatry. Oxford: Oxford University Press. 